\title{
Controlled photothermal therapy based on temperature monitoring: theoretical and experimental analysis
}

\author{
Annalisa Orrico \\ Department of Mechanical Engineering \\ Politecnico di Milano \\ Milan, Italy \\ annalisa.orrico@mail.polimi.it
}

\author{
Martina De Landro \\ Department of Mechanical Engineering \\ Politecnico di Milano \\ Milan, Italy \\ martina.delandro@polimi.it
}

\author{
Leonardo Bianchi \\ Department of Mechanical Engineering \\ Politecnico di Milano \\ Milan, Italy \\ leonardo.bianchi@polimi.it \\ Paola Saccomandi \\ Department of Mechanical Engineering \\ Politecnico di Milano \\ Milan, Italy \\ paola.saccomandi@polimi.it
}

\author{
Sanzhar Korganbayev \\ Department of Mechanical Engineering \\ Politecnico di Milano \\ Milan, Italy \\ sanzhar.korganbayev@polimi.it
}

\begin{abstract}
Real-time monitoring and temperature-based control are beneficial for optimizing the outcomes of thermal ablation treatments. In this paper, simulations and experiments were performed to investigate the efficacy of the temperaturefeedback control system in confining the thermal damaged area and in maintaining the setpoint temperature. The implemented control system adjusts the laser source power based on the maximum temperature values measured by fiber Bragg grating sensors. The theoretical model predicts the thermal response of the biological tissue under different control parameters and allows calculating the produced thermal damage. Different setpoint temperatures ranging from $43{ }^{\circ} \mathrm{C}$ to $60^{\circ} \mathrm{C}$ were chosen to evaluate their effects on the irradiated tissue region, in terms of temperature trend and thermal damage. The numerical results are validated by the experimental temperature trends obtained applying the same control strategy. Finally, both the simulation results and experiment outcomes show the capability of the control system to confine the tissue thermal damaged area by performing a laser ablation procedure almost at the set temperature.
\end{abstract}

Keywords-temperature-feedback control, fiber optic sensors, thermal therapy, photothermal therapy, simulations, measurement instrumentation.

\section{INTRODUCTION}

Thermotherapy techniques are being performed as a standard procedure to treat unresectable tumors [1]. Laser Ablation (LA) is a minimal invasiveness treatment that allows having a shorter recovery time and a lower risk of unwanted effects after the treatment. In particular, it has been proven that LA can treat many primary and secondary neoplasms [2]. The treated tissue healing response depends on the reached degree of thermal injury [3], and the exposure time and temperature involved are decisive parameters to determine the degree of thermal damage at the end of treatments [4]. The temperatures reached during the photothermal procedure leads to specific

This project has received funding from the European Research Council (ERC) under the European Union's Horizon 2020 research and innovation programme (Grant agreement No. 759159).

This work has been supported by the research project "HyperSIGHT" (ID R18SF4YHHS) funded by the Italian Ministry of University and Research (Call FARE Ricerca 2018). biological effects, therefore they can be used to categorize the different regions of the treated area: temperatures comprised between $41^{\circ} \mathrm{C}$ and $45^{\circ} \mathrm{C}$ lead to a reversible thermal damaged area, and temperatures above $50{ }^{\circ} \mathrm{C}$ produce an irreversible thermal damage zone (due to an enzyme activity reduction) [5]. Consequently, the use of a feedback control system based on real-time tissue temperature measurements can be decisive in minimizing unwanted thermal injury during LA. In fact, various temperature-controlled systems have been implemented based on thermocouples [6] and thermistors [7]. Thermocouple and thermistor probes are made of metallic material, thus they could absorb laser light experiencing selfheating that leads to measurement errors. Moreover, being single-point measurement instruments, they are characterized by low spatial resolution. Recently, our group has established the first strategy with fiber Bragg grating (FBG) sensors for controlling LA based on temperature measurements [8], [9]. Being characterized by low heat conductivity, immunity to electromagnetic interferences, and having the multiplexing capability, these sensors are compatible with LA treatments [10].

The current study aims at improving the efficacy of FBGassisted LA, by predicting and evaluating the performances of the control-strategy on the target tissue through a numerical model. To limit the increase of tissue surface temperature, controlled LA was performed based on an ON-OFF control algorithm triggered by FBG sensors. Both numerical modeling and experimental analysis were implemented for different setpoint temperatures $\mathrm{T}_{\mathrm{s}}$ (i.e. $60{ }^{\circ} \mathrm{C}, 55^{\circ} \mathrm{C}, 48{ }^{\circ} \mathrm{C}$, and $43^{\circ} \mathrm{C}$ ) to evaluate the degree of thermal injury and the tissue temperature distribution.

\section{MATERIAL AND METHODS}

\section{A. Temperature control logic}

The temperature feedback control-loop is based on the ON-OFF control algorithm which establishes the current-state of the laser source according to the real-time measured 
temperature value. The laser current is switched to the OFF state (laser power $\mathrm{P}=0 \mathrm{~W}$ ) when the maximum value of the measured temperatures exceeds the setpoint value $T_{s}$, otherwise, it is switched to the $\mathrm{ON}$ state (laser power $\mathrm{P}=2$ $\mathrm{W})$.

To prevent possible overloading of the laser source equipment, the time interval $(\Delta \tau)$ that regulates the change of the laser current-state does not correspond to the acquisition time interval of temperature measurements $\left(\tau_{\mathrm{T}}<0.1 \mathrm{~s}\right)$. The temperature control logic aims at maintaining the maximum temperature measured at the setpoint value, and for contactless LA it has been proven that $\Delta \tau=1 \mathrm{~s}$ allows a smooth temperature control [9]; hence, $\Delta \tau$ was set to $1 \mathrm{~s}$ in this study. Different $\mathrm{T}_{\mathrm{s}}$ (i.e., $60^{\circ} \mathrm{C}, 55^{\circ} \mathrm{C}, 48{ }^{\circ} \mathrm{C}$, and $43{ }^{\circ} \mathrm{C}$ ) were tested using the temperature-feedback controlled LA. To analyze the benefits of the controlled LA, also an uncontrolled LA experiment was conducted.

\section{B. Numerical simulations}

Numerical simulations were carried out to foresee the effects of the temperature feedback control-loop on the temperature distribution and the thermal damage extension. The numerical model of the contactless LA procedure was solved by using a Finite Element Method (FEM) solver, COMSOL Multiphysics (COMSOL, Inc., Burlington, MA, USA).

Based upon the experimental setup, one FBG array (i.e., inner diameter $=0.125 \mathrm{~mm}$ of silica glass and outer diameter

(a) 3D model of the tissue specimen

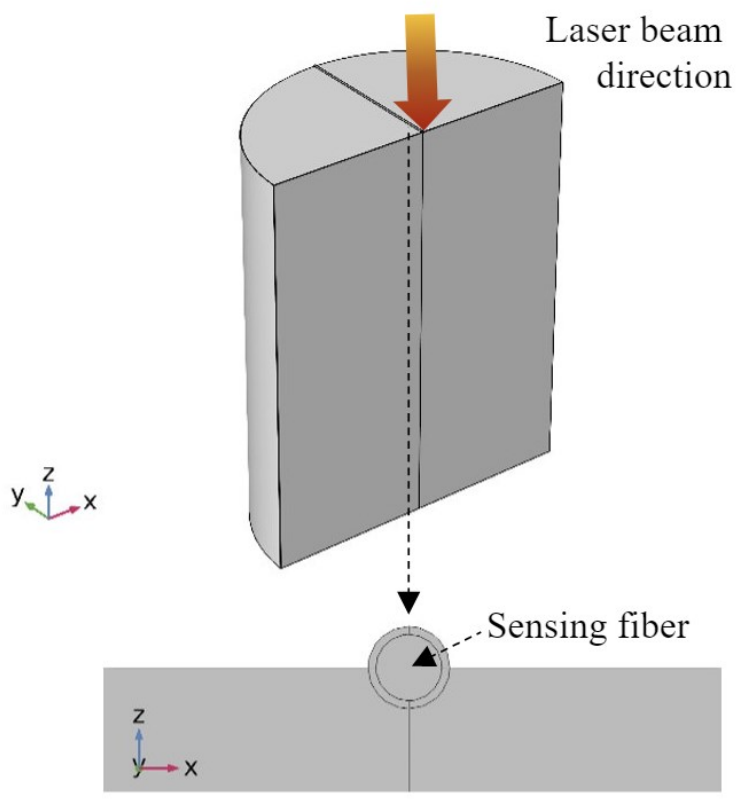

(b) Detail of the cross-section of the sensing fiber

Fig. 1. Simulation geometry of porcine liver phantom and fiber Bragg grating array. In (a) it is reported the three-dimensional view $(x-y-z)$ of the geometry. In (b) it is shown the frontal zoom (z-x) to highlight the position of the fiber on the phantom.
$=0.155 \mathrm{~mm}$ of polyimide) was designed above a half-cylinder of $10 \mathrm{~mm}$ in radius by $25 \mathrm{~mm}$ thickness representing the porcine liver tissue specimen used for further experimental evaluation (Fig. 1).

The bio-heat equation (1) was used to model the tissue thermal response to an external heat source. This is the first and most largely employed model of heat transfer in biological tissues proposed by Pennes [6] [11] [12], based on Fourier's law:

$$
\rho \cdot \mathrm{c} \cdot \frac{\partial \mathrm{T}}{\partial \mathrm{t}}+\nabla(-\mathrm{k} \cdot \nabla \mathrm{T})=\mathrm{Q}_{\mathrm{laser}}
$$

where $\rho\left(\mathrm{kg} \cdot \mathrm{m}^{-3}\right), \mathrm{c}\left(\mathrm{J} \cdot \mathrm{kg}^{-1} \cdot \mathrm{K}^{-1}\right)$, and $\mathrm{k}\left(\mathrm{W} \cdot \mathrm{m}^{-1} \cdot \mathrm{K}^{-1}\right)$ are the density, the specific heat, and the thermal conductivity of tissue, respectively; $\mathrm{T}(\mathrm{K})$ is the local tissue temperature, and $\mathrm{Q}_{\text {laser }}\left(\mathrm{W} \cdot \mathrm{m}^{-3}\right)$ is the external heat source brought by the laser light. The external heat generated by the laser-tissue interaction can be modeled according to the Beer-Lambert law [13]:

$$
\mathrm{Q}_{\text {laser }}=\alpha_{\mathrm{a}} \cdot \mathrm{I} \cdot \exp \left(-\alpha_{\mathrm{a}} \cdot \mathrm{d}\right)
$$

where $\alpha_{\mathrm{a}}\left(\mathrm{m}^{-1}\right)$ is the absorption coefficient, $\mathrm{d}(\mathrm{m})$ is the axial depth in tissue, and $\mathrm{I}\left(\mathrm{W} \cdot \mathrm{m}^{-2}\right)$ is the laser irradiance. A nearinfrared wavelength is employed on biological material, leading to a non-negligible optical scattering phenomenon formation. To model the absorption and the scattering contribution an effective attenuation coefficient $\alpha_{\text {eff }}$ was used in (2) instead of $\alpha_{a}$ [14].

The convective heat transfer equation (3) was included in the model as boundary condition [15] to consider the influence of air on the irradiated surface during the contactless LA procedure.

$$
-\mathrm{k} \cdot \nabla \mathrm{T}=\mathrm{q}_{\mathrm{c}, 0}=\mathrm{h} \cdot\left(\mathrm{T}_{\mathrm{ext}}-\mathrm{T}\right) \quad \text { on } \quad \partial \sigma
$$

where $\mathrm{q}_{\mathrm{c}, 0}\left(\mathrm{~W} \cdot \mathrm{m}^{-2}\right)$ is the heat exchanged with the surrounding air, $\mathrm{h}\left(\mathrm{W} \cdot \mathrm{m}^{-2} \cdot \mathrm{K}^{-1}\right)$ is the air convective heat transfer coefficient, $\mathrm{T}_{\text {ext }}(\mathrm{K})$ is the ambient air temperature, and $\partial \sigma$ is the external surface subjected to the heat flux.

To calculate the degree of tissue injury $\Omega(t)$ during the laser irradiation procedure, the Arrhenius equation [16] was considered in the model, according to:

$$
\Omega(t)=A_{f} \cdot \int_{0}^{\tau} \exp \left(-\frac{E_{a}}{R \cdot T(t)}\right) d t
$$

where $A_{f}\left(s^{-1}\right)$ is the frequency factor, $E_{a}\left(J \cdot \mathrm{mol}^{-1}\right)$ the denaturation activation energy, $\mathrm{R}\left(\mathrm{J} \cdot \mathrm{mol}^{-1} \cdot \mathrm{K}\right)$ is the universal gas constant, and $\tau(\mathrm{s})$ is the irradiation time. At $\Omega(\mathrm{t})=1$ the probability of cell destruction is equal to $63 \%$ [17], hence this threshold was used to identify the necrotic tissue region.

\section{Experimental setup}

Contactless LA experiments were performed with an 808 $\mathrm{nm}$ diode laser. The laser light was delivered on the surface of an ex vivo porcine liver through a multimode $440 \mu \mathrm{m}$ diameter quartz optical fiber connected to a collimator (OZ Optics Ltd., Ottawa, Canada). The thermal ablation was performed with 2 $\mathrm{W}$ laser power during the $\mathrm{ON}$ current-state and with a laser 
irradiation duration of $90 \mathrm{~s}$ (made of heating phase and controlling phase). The sensing region of one FBG array (consisting of 40 sensors placed at $10 \mu \mathrm{m}$ edge-to-edge distance, SM1500(9/125)P, Fibercore Ltd., Southampton, UK) was placed on the phantom surface in correspondence of the laser spot. The sensing length of the whole array covers $4.8 \mathrm{~cm}$. The control algorithm was designed and implemented in LabVIEW; the program receives through the Micron Optics si255 interrogation unit the real-time Bragg wavelength values $\lambda_{\mathrm{B}}(\mathrm{T}, \mathrm{t})$ and converts them into temperature measurements $\mathrm{T}(\mathrm{t})$; based on these measurements, the algorithm changes the laser current-state $\mathrm{I}(\mathrm{t})$ at the chosen $\Delta \tau$. Fig. 2 depicts the experimental setup and the implemented control strategy.

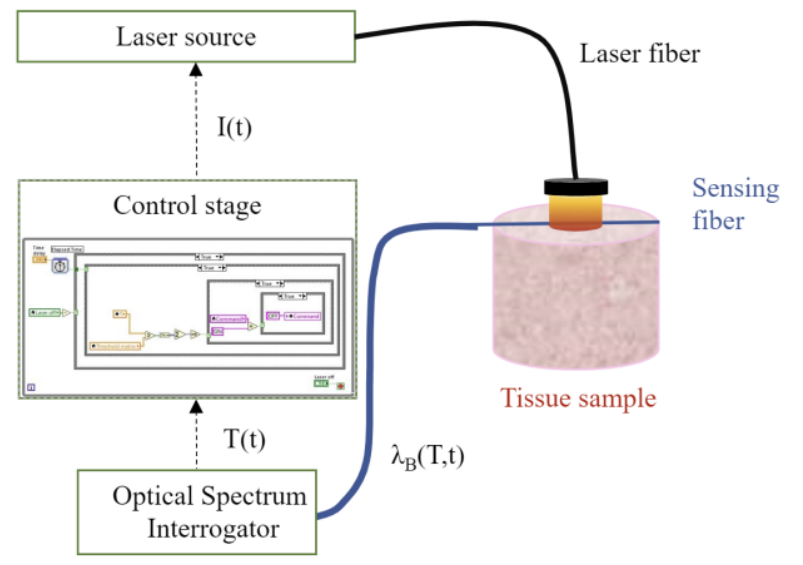

Fig. 2. Schematic illustrations on the experimental setup for tissue testing under thermal treatment controlled with the implemented strategy for laser current control.

\section{RESULTS}

Fig. 3 reports the temperature maps of the controlled simulations for the following $\mathrm{T}_{\mathrm{s}}: 60^{\circ} \mathrm{C}, 55^{\circ} \mathrm{C}, 48^{\circ} \mathrm{C}$, and 43 ${ }^{\circ} \mathrm{C}$; on the left, the cases at the moment in which the maximum temperature (maximum peak) is reached are reported. Conversely, on the right, the temperature distributions when the minimum temperature is recorded during the controlled phase of LA are shown.

Fig. 4. reports the power profiles for different $T_{\mathrm{s}}$. We can observe that the time needed to activate the power control is dependent on the value of $\mathrm{T}_{\mathrm{s}}$ : higher setpoint temperatures require longer times to trigger the first ON-OFF. Indeed, it ranges from $34 \mathrm{~s}$ in the case of $\mathrm{T}_{\mathrm{s}}=60^{\circ} \mathrm{C}$, to $10 \mathrm{~s}$ for $\mathrm{T}_{\mathrm{s}}=43$ ${ }^{\circ} \mathrm{C}$. For higher $\mathrm{T}_{\mathrm{s}}$, the number of times in which the laser was in OFF state is lower since the heating phase lasts more (as stated before, longer times are needed to reach higher $\mathrm{T}_{\mathrm{s}}$ ).

As shown in Fig. 5, the experimental temperature profiles follow the trends predicted by the simulations. The temperature profile similarity between the experiments and simulations can be further improved by a deep analysis of raising times and peak temperatures. The raising time is the time needed to reach the setpoint temperature (duration of the heating phase). The raising times last: $10 \mathrm{~s}, 14.6 \mathrm{~s}, 23.9 \mathrm{~s}$, and $33.7 \mathrm{~s}$ for the experiments and $11.1 \mathrm{~s}, 16 \mathrm{~s}, 25.2 \mathrm{~s}$, and $34.3 \mathrm{~s}$ during the simulations for the $\mathrm{T}_{\mathrm{s}}$ equal to $43^{\circ} \mathrm{C}, 48^{\circ} \mathrm{C}, 55^{\circ} \mathrm{C}$, and $60{ }^{\circ} \mathrm{C}$, correspondingly. It is also important to assess the

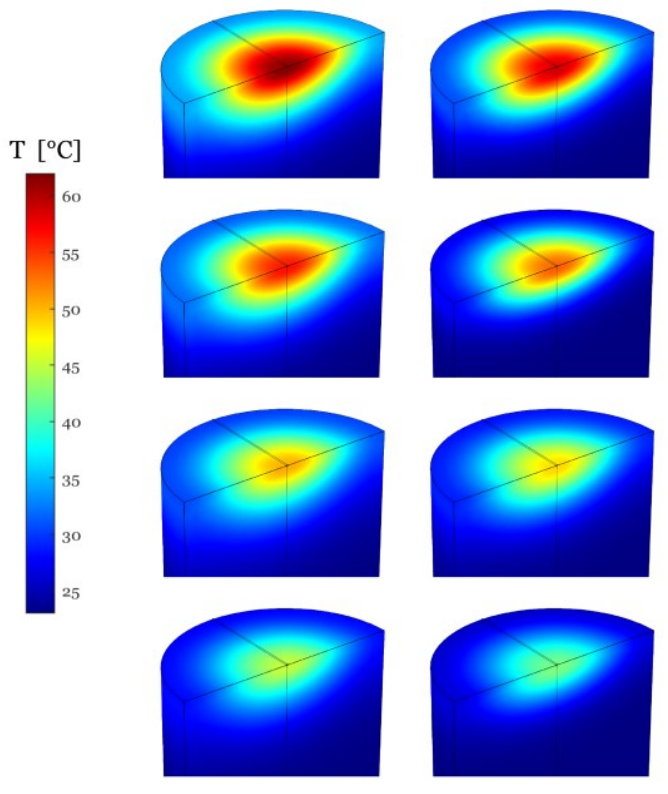

Fig. 3. Three-dimensional temperature distributions when the maximum (on the left) and minimum temperatures (on the right) are reached during the controlled phase of LA for setpoint temperature $T_{s}$ equal to (a) 60 ${ }^{\circ} \mathrm{C}$; (b) $55^{\circ} \mathrm{C}$; (c) $48{ }^{\circ} \mathrm{C}$, and (d) $43^{\circ} \mathrm{C}$.
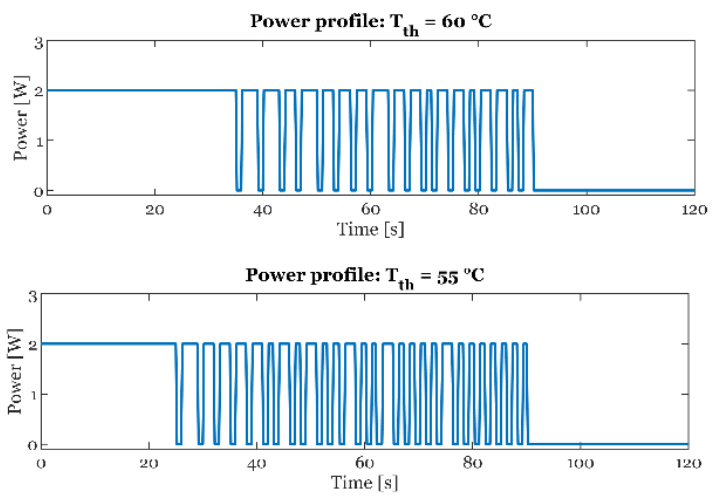

Power profile: $\mathrm{T}_{\text {th }}=48^{\circ} \mathrm{C}$
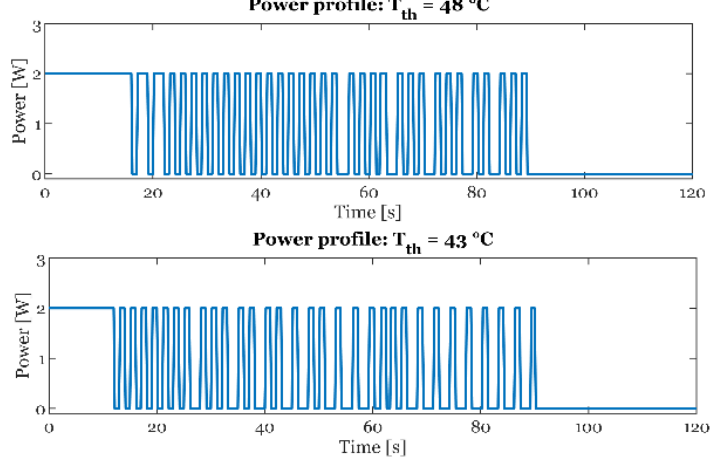

Fig. 4. Power profiles of controlled LA simulations for setpoint temperatures $\mathrm{T}_{\mathrm{s}}$ equal to (a) $60{ }^{\circ} \mathrm{C}$; (b) $55^{\circ} \mathrm{C}$; (c) $48^{\circ} \mathrm{C}$, and (d) $43{ }^{\circ} \mathrm{C}$.

peak temperature value since it can lead to an unwanted thermal effect and consecutive damage in the tissue. Peaks are present in both simulations and experiments; the maximum overshoots are: $2.2{ }^{\circ} \mathrm{C}, 2.1{ }^{\circ} \mathrm{C}, 1.7{ }^{\circ} \mathrm{C}$, and $1.7{ }^{\circ} \mathrm{C}$ for simulations, and $2.3{ }^{\circ} \mathrm{C}, 2.2{ }^{\circ} \mathrm{C}, 1.9{ }^{\circ} \mathrm{C}$, and $2.0{ }^{\circ} \mathrm{C}$ for experiments, at $\mathrm{T}_{\mathrm{s}}$ equal to $43{ }^{\circ} \mathrm{C}, 48{ }^{\circ} \mathrm{C}, 55^{\circ} \mathrm{C}$, and $60{ }^{\circ} \mathrm{C}$, respectively. The chosen $\mathrm{T}_{\mathrm{s}}$ affects the temperature values reached inside the heated region and its extension, as it can be seen from Fig. 3. Since the thermal damage is a function of 

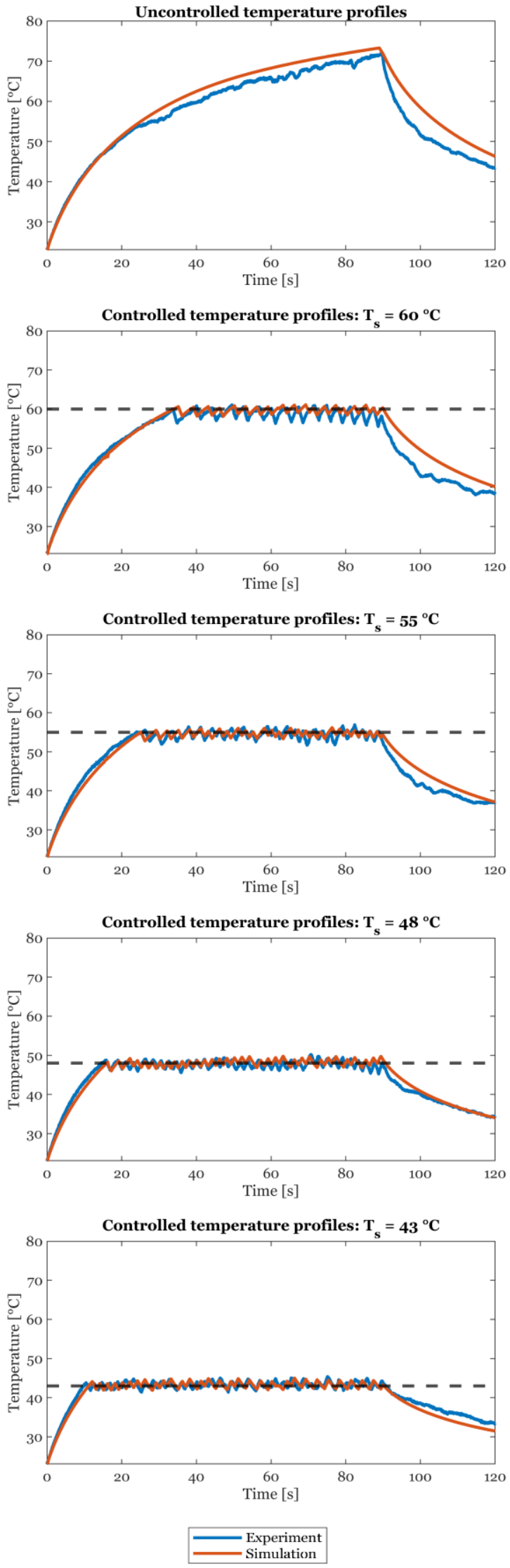

Fig. 5. Maximum temperature profiles of experiments (blue line) and simulations (red line) obtained from uncontrolled LA (a) and different set point temperatures $\mathrm{T}_{\mathrm{s}}$ equal to (b) $60^{\circ} \mathrm{C}$; (c) $55^{\circ} \mathrm{C}$; (d) $48{ }^{\circ} \mathrm{C}$, and (e) 43 ${ }^{\circ} \mathrm{C}$. the reached temperature and the exposure time, being the latter fixed, the adopted setpoint temperature influences the degree of injury and its extension. This can be clearly seen on the left of Fig. 6 that shows the treated tissue at the end of the experimental LA procedure. The uncontrolled LA has the largest and most clearly defined thermally affected area with an inner region of ablated tissue. A smaller defined thermal affected area is present for $\mathrm{T}_{\mathrm{s}}=60{ }^{\circ} \mathrm{C}$ and $55^{\circ} \mathrm{C}$ without a region of visible ablated area. For $\mathrm{T}_{\mathrm{s}}=48{ }^{\circ} \mathrm{C}$ and $43{ }^{\circ} \mathrm{C}$, it is difficult to macroscopically observe the boundary of the thermally affected area. On the right of Fig. 6, the different effects at the end of the LA simulations are reported. The area of necrotic tissue was observed only for the uncontrolled LA case. To consider also the thermally affected areas the following thresholds have been considered: $\mathrm{T} \geq 50^{\circ} \mathrm{C}$ (that corresponds to an enzyme activity reduction) and $\mathrm{T} \geq 43{ }^{\circ} \mathrm{C}$ (that indicates a change in the cells conformation). This last threshold has been represented only if the tissue experienced $43{ }^{\circ} \mathrm{C}$ at least for one minute. For $120 \mathrm{~s}$ of LA procedure (including $30 \mathrm{~s}$ of cooling phase), the temperature-feedback control was able to hinder the growth of the thermally affected area.
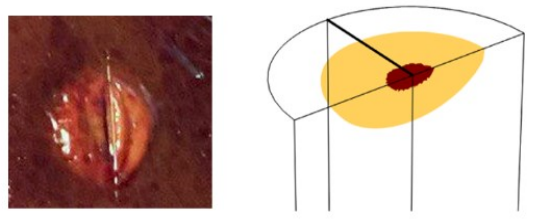

(a)
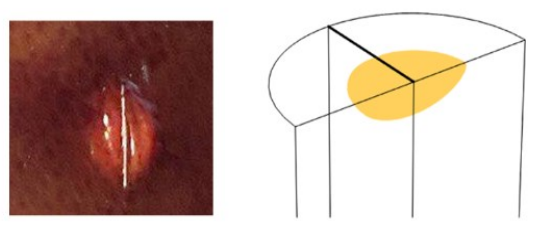

(b)
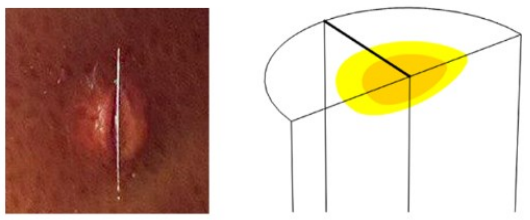

(c)
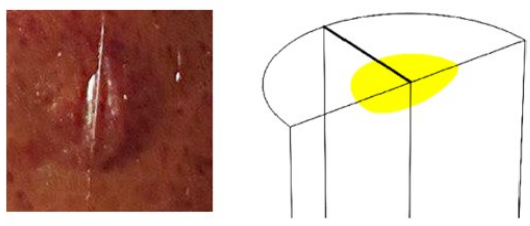

(d)
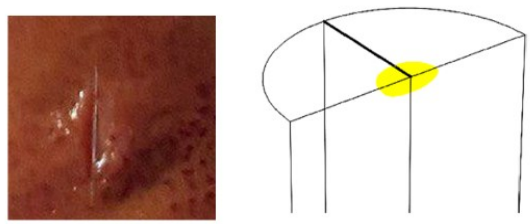

(e)

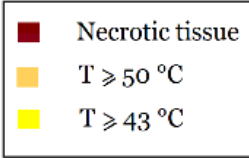

Fig. 6. Thermal damaged areas of the experiments (left) and simulations (right) for the uncontrolled case (a) and different setpoint temperatures $\mathrm{T}_{\mathrm{s}}$ equal to (b) $60^{\circ} \mathrm{C}$; (c) $55^{\circ} \mathrm{C}$; (d) $48{ }^{\circ} \mathrm{C}$, and (e) $43^{\circ} \mathrm{C}$. 


\section{DISCUSSION AND CONCLUSIONS}

Both numerical simulations and experiments validate the ON-OFF control algorithm, developed to limit the maximum temperature and therefore prevent undesirable thermal effects on the treated tissue. To identify the advantages of controlled LA treatment, two different irradiation modalities (ON-OFF controlled and uncontrolled) were compared numerically and experimentally. During the uncontrolled case, the temperatures involved are elevated leading to undesired and irreversible tissue thermal damage (cell necrosis). In the case of controlled LA, different experiments were performed to evaluate the thermal tissue response to different $\mathrm{T}_{\mathrm{s}}$ (i.e. $60^{\circ} \mathrm{C}$, $55{ }^{\circ} \mathrm{C}, 48{ }^{\circ} \mathrm{C}$, and $43{ }^{\circ} \mathrm{C}$ ). As a result, irreversible thermal damage occurs without cell necrosis formation at $\mathrm{T}_{\mathrm{s}}=60^{\circ} \mathrm{C}$ and $\mathrm{T}_{\mathrm{s}}=55{ }^{\circ} \mathrm{C}[18]$; for the remaining $\mathrm{T}_{\mathrm{s}}$, only reversible thermal effects are present at the end of the laser irradiation (which lasts $90 \mathrm{~s}$ ).

In this paper, a theoretical model has been developed as a preliminary pre-operative treatment planning tool to find the laser setting parameters in order to optimize the outcomes of LA. Photothermal-induced heat-transfer in biological tissue is a complex phenomenon and numerical results of theoretical models may divert from experimental values [6]. The complexity of the treatment, along with the specific mechanical, thermal, and optical properties of the tissue and the non-ideal physiological conditions, usually limits the repeatability of the thermal effect [8] thus can impair the final clinical outcome. This is one of the main motivations at the basis of the need of a real-time temperature control strategy. Our control strategy is based on the temperature measurements provided by the FBG array. The chosen measurement system is more compatible with LA than conventional measurement techniques. Indeed, with respect to single-point temperature measurement systems, the highlydense FBG array is characterized by higher spatial resolution [8] allowing the detection of high-gradient temperature profiles and by lower laser light absorption; both characteristics lead to an accurate evaluation of the temperature distribution, also in in vivo cases [19]. With respect to contactless thermometric systems, the FBG array is also suitable to implement a temperature feedback controlloop for interstitial laser ablation. [20]

The availability of a theoretical model that accurately predicts the thermal response of the tissue is fundamental to design the control parameters $\left(\mathrm{T}_{\mathrm{s}}\right.$, in this study) and to perform a preliminary analysis of the control strategy adequate for the target. The numerical and experimental results, here presented, prove the effectiveness of the designed control strategy, and the influence of the chosen setpoint temperature on the nature and the extension of thermal damage.

Some improvements of this study can go in two main directions, one associated with the control strategy, and one related to the model used for studying the heat-transfer in tissues. Indeed, the ON-OFF control algorithm here presented limits the maximum temperature without eliminating the presence of peaks due to the temperature oscillations around the setpoint temperature. The implementation of a proportional-integrative-derivative (PID) controller might mitigate the mentioned limitation in future works. Lastly, the theoretical model should be developed to simulate the control parameters in a more complex scenario, like in vivo perfused organs.

\section{ACKNOWLEDGMENT}

The authors would like to acknowledge Alexey Wolf and Alexander Dostovalov at the Institute of Automation and Electrometry of the SB RAS, Novosibirsk (Russia) for producing FBG arrays for our measurements.

This project has received funding from the European Research Council (ERC) under the European Union's Horizon 2020 research and innovation programme (Grant agreement No. 759159).

This work has been supported by the research project "HyperSIGHT" (ID R18SF4YHHS) funded by the Italian Ministry of University and Research (Call FARE Ricerca 2018).

\section{REFERENCES}

[1] S. N. Goldberg, G. S. Gazelle, and P. R. Mueller, "Thermal Ablation Therapy for Focal Malignancy," Am. J. Roentgenol., vol. 174, no. 2, pp. 323-331, 2000, doi: 10.2214/ajr.174.2.1740323.

[2] F. M. Di Matteo et al., "Feasibility of EUS-guided Nd:YAG laser ablation of unresectable pancreatic adenocarcinoma," Gastrointest. Endosc., 2018, doi: 10.1016/j.gie.2018.02.007.

[3] M. Rieken, H. W. Kang, E. Koullick, G. R. Ruth, and A. Bachmann, "Laser vaporization of the prostate in vivo: Experience with the $150-\mathrm{W}$ 980-nm diode laser in living canines," Lasers Surg. Med., vol. 42, no. 8, pp. 736-742, 2010, doi: 10.1002/lsm.20966.

[4] A. Vogel and V. Venugopalan, "Mechanisms of pulsed laser ablation of biological tissues," Chem. Rev., vol. 103, no. 2, pp. 577-644, 2003, doi: $10.1021 / \mathrm{cr} 010379$ n.

[5] K. F. Chu and D. E. Dupuy, "Thermal ablation of tumours: Biological mechanisms and advances in therapy," Nat. Rev. Cancer, vol. 14, no. 3, pp. 199-208, 2014, doi: 10.1038/nrc3672.

[6] T. H. Nguyen, S. Park, K. K. Hlaing, and H. W. Kang, "Temperature feedback-controlled photothermal treatment with diffusing applicator: theoretical and experimental evaluations," Biomed. Opt. Express, vol. 7, no. 5, p. 1932, 2016, doi: 10.1364/boe.7.001932.

[7] P. H. Möller, L. Lindberg, P. H. Henriksson, B. R. R. Persson, and K G. Tranberg, "Temperature control and light penetration in a feedback interstitial laser thermotherapy system," Int. J. Hyperth., vol. 12, no. 1, pp. 49-63, 1996, doi: 10.3109/02656739609023689.

[8] S. Korganbayev et al., "Closed-Loop Temperature Control Based on Fiber Bragg Grating Sensors for Laser Ablation of Hepatic Tissue," Sensors, vol. 20, 2020, doi: 10.3390/s20226496.

[9] S. Korganbayev, R. Pini, A. Orrico, A. Wolf, A. Dostovalov, and P. Saccomandi, "Towards temperature-controlled laser ablation based on fiber Bragg grating array temperature measurements," 2020 IEEE Int. Work. Metrol. Ind. 4.0 IoT, MetroInd 4.0 IoT 2020 - Proc., pp. 268272, 2020, doi: 10.1109/MetroInd4.0IoT48571.2020.9138171.

[10] F. Morra et al., "Spatially resolved thermometry during laser ablation in tissues: Distributed and quasi-distributed fiber optic-based sensing," Opt. Fiber Technol., vol. 58, no. June, p. 102295, 2020, doi: 10.1016/j.yofte.2020.102295.

[11] Harry H. Pennes, "Analysis of tissue and arterial blood temperatures in the resting human forearm," J. Appl. Physiol., vol. I, 1948.

[12] S. Singh and R. Repaka, "Quantification of Thermal Injury to the Healthy Tissue Due to Imperfect Electrode Placements During Radiofrequency Ablation of Breast Tumor," J. Eng. Sci. Med. Diagnostics Ther., vol. 1, no. 1, pp. 1-10, 2018, doi: 10.1115/1.4038237.

[13] P. Saccomandi et al., "Theoretical analysis and experimental evaluation of laser-induced interstitial thermotherapy in ex vivo porcine pancreas," IEEE Trans. Biomed. Eng., vol. 59, no. 10, pp. 2958-2964, 2012, doi: 10.1109/TBME.2012.2210895.

[14] A. Ishimaru, "Diffusion of light in turbid material," Appl. Opt., vol. 28, no. 12 , p. 2210, 1989, doi: 10.1364/ao.28.002210.

[15] C. Multiphysics, "Heat Transfer Module,” Manual, pp. 1-222, 2015. 
[16] Markolf H. Niemz, Laser-tissue Iteractions: Fundamentals and Applications. Springer-Verlag, 2004.

[17] P. Gas and E. Kurgan, "Evaluation of thermal damage of hepatic tissue during thermotherapy based on the arrhenius model," 2018 Prog. Appl. Electr. Eng. PAEE 2018, pp. 18-21, 2018, doi: 10.1109/PAEE.2018.8441065.

[18] M. De Landro et al., "Hyperspectral imagery for assessing laserinduced thermal state change in liver," Sensors (Switzerland), vol. 21, no. 2, pp. 1-19, 2021, doi: 10.3390/s21020643.
[19] L. Bianchi et al., "Fiber Bragg Grating Sensors for Thermometry during Gold Nanorods-mediated Photothermal Therapy in Tumor Model," 2020, doi: 10.1109/SENSORS47125.2020.9278580.

[20] L. Bianchi, S. Korganbayev, A. Orrico, M. De Landro, and P. Saccomandi, "Quasi-distributed fiber optic sensor-based control system for interstitial laser ablation of tissue: theoretical and experimental investigations," Biomed. Opt. Express, 2021, doi: 10.1364/BOE.419541. 